\title{
Evaluation of Antibacterial Effect by Using a Fibrous Grafted Material Loaded Ag Ligand
}

\author{
Takuya Shibata*, Noriaki Seko, Noboru Kasai, Hiroyuki Hoshina, Yuji Ueki \\ Quantum Beam Science Center, Sector of Nuclear Science Research, Japan Atomic Energy Agency, Takasaki, \\ Japan \\ Email: shibata.takuya@jaea.go.jp
}

Received 28 May 2015; accepted 27 June 2015; published 30 June 2015

Copyright $@ 2015$ by authors and Scientific Research Publishing Inc.

This work is licensed under the Creative Commons Attribution International License (CC BY).

http://creativecommons.org/licenses/by/4.0/

(c) () Open Access

\section{Abstract}

To obtain the safety of drinking water, an antibacterial material was prepared by loading silver (Ag) onto fibrous iminodiacetate (IDA) adsorbent, which was synthesized by radiation-induced graft polymerization of glycidyl methacrylate and subsequent chemical modification of the produced epoxy group to an IDA group (IDA-Ag). A total amount of loaded Ag on the IDA-Ag fabric was $0.4 \mathrm{mmol}-\mathrm{Ag} / \mathrm{g}$-fabric. From an observation of the IDA-Ag fabric cross section by a scanning electron microscope energy dispersive $\mathrm{X}$-ray spectrometer, $\mathrm{Ag}$ was distributed to IDA layer uniformly. As a result of evaluating antibacterial effects by the column mode water flow test with stream water, the effective Ag concentration was monitored $0.05 \mathrm{ppm}$ at irrespective flow rate which was functioned to the antibacterial performance. The antibacterial effects for general bacteria were indicated until BV (BV: steam water volume/IDA-Ag fabric volume) 6000, and for colitis germ legions were completely disinfected until BV 6000.

\section{Keywords}

Antibacterial Material, Radiation Induced Graft Polymerization, Silver, Iminodiacetate, Drinking Water

\section{Introduction}

The general bacteria and colitis germ legions could be contaminated from natural water resources easily. Since stream water and well water are directly used for life water without any disinfection at mountain areas, the safely water supply was demanded as the daily water resources. Especially, the disaster areas caused by an accident at the Fukushima Daiichi Nuclear Power Station widely distributed radioactive materials. Therefore, we have

\footnotetext{
"Corresponding author.
}

How to cite this paper: Shibata, T., Seko, N., Kasai, N., Hoshina, H. and Ueki, Y. (2015) Evaluation of Antibacterial Effect by Using a Fibrous Grafted Material Loaded Ag Ligand. International Journal of Organic Chemistry, 5, 100-107. 
developed a high-performance adsorbent for cesium (Cs) removal [1]. During usage of our Cs removal system, the proliferation bacteria were observed in discharged water effluent.

Many technique have been proposed for antibacterial effects such as poly(amic) acid [2], chitosan [3] [4], enzyme [5], and metal ions [6]. Antibacterial effects of metal ions are well known for a long time, although mechanisms are not clarified yet [7]. Metal ions such as titanium [8]-[11], copper [6] [9] [10], zinc [6], and silver (Ag) [6]-[9] [12]-[15] were investigated for developing antibacterial materials. Especially, the study of loading Ag to materials for having antibacterial effect is one of the focuses because Ag nanoparticle has antibacterial effects to a broad spectrum such as Gram-negative and Gram-positive bacteria [16]. Besides, Ag concentration ranging from 0.025 to $0.1 \mathrm{ppm}$ had a suitable condition for antibacterial effects for drinking water and mineral water [17].

Radiation-induced graft polymerization (RIGP) is well known as a superior technique for the introduction of functional groups into polymeric materials with various shapes. In the case of RIGP, a metal adsorbent could be synthesized by introducing the chelate function to a trunk polymeric material [18] [19]. Grafted adsorbent of iminodiacetate (IDA) type had high affinity for many kinds of metals such as cadmium [20] [21] and lead [21] [22], and the adsorbed metals on the adsorbent could be easily eluted with an acid [23] [24].

In this study, an antibacterial material with loading Ag was synthesized by RIGP of glycidyl methacrylate (GMA) onto a polyethylene nonwoven fabric (NF) and subsequent chemical modification with IDA. The continuous antibacterial evaluation was investigated for the resultant IDA-Ag fabric with the stream water.

\section{Experiment}

\subsection{Materials and Chemicals}

A trunk NF composed of polyethylene coated to polypropylene was purchased from Kurashiki Textile Manufacturing Co., Ltd. GMA from Mitsubishi Gas Chemical Company, INC. and polyoxethylene sorbitan monolaurate (Tween 20) from Kanto Chemical Co., Ltd. were purchased for the grafting. Iminodiacetate disodium (IDA$\mathrm{Na}$ ) and ethanol (EtOH) from Wako Pure Chemical Industries, Ltd. were purchased for the introduction of IDA group to the propagated epoxy group of GMA. Ag nitrate from Kanto Chemical Co., Ltd. was purchased for loading Ag as an antibacterial group on IDA. Nitric acid from Wako Pure Chemical Industries, Ltd. was purchased for protonation of IDA-Na to IDA-H. Ammonia from Wako Pure Chemical Industries, Ltd. was purchased for adjustment of $\mathrm{pH}$. Distilled water for washing after reactions and ultrapure water for diluting solutions was obtained by Millie-Q system from Merck Ltd. Methanol (MeOH) purchased from Taiyo Chemical Industry Co., Ltd. were used a washing solvent for grafted NF. The stream water at Fukushima prefecture, Japan filtered by $50 \mu \mathrm{m}$ was used as test water for antibacterial test.

\subsection{Synthesis of the IDA-Ag Fabric}

Figure 1 shows the schematic procedure of the IDA-Ag fabric as the antibacterial material. The NF was used as the trunk polymer for the grafting of GMA. The NF cut into a certain size and packed into polyethylene bags, and was irradiated with $20 \mathrm{kGy}$ by an electron beam in a nitrogen gas atmosphere at dry ice temperature. Next, the irradiated NF immediately immersed into a deaerated monomer solution, which was prepared by $5 \mathrm{wt} \%$ GMA, $0.5 \mathrm{wt} \%$ Tween 20, and $94.5 \mathrm{wt} \%$ ultrapure water, for $2 \mathrm{~h}$ at $40^{\circ} \mathrm{C}$. After grafting, the GMA-grafted NF (GMA-g) was washed by distilled water and $\mathrm{MeOH}$, and dried in a vacuum oven at $40^{\circ} \mathrm{C}$. The yield of the grafting was evaluated in terms of the degree of grafting (DG), which is calculated by

$$
\mathrm{DG}[\%]=100\left[\left(W_{1}-W_{0}\right) / W_{0}\right] \text {, }
$$

where $W_{0}$ is the weight of the NF before grafting, and $W_{1}$ is the weight of the GMA-g.

The resulting GMA-g having DG $190 \%$ was modified with $0.4 \mathrm{~mol} / \mathrm{L}$ of IDA-Na solutions to prepared the IDA-Na adsorbent (IDA-ad). The solvent was prepared by $50 \mathrm{vol} \%$ of ultrapure water and $50 \mathrm{vol} \%$ of EtOH for converting of the propagated epoxy groups of GMA to IDA groups. The modification reaction was carried out by keeping for $24 \mathrm{~h}$ at $60^{\circ} \mathrm{C}$. The resulting IDA-ad was immersed in $0.5 \mathrm{~mol} / \mathrm{L}$ of nitric acid for $3 \mathrm{~h}$ at $60^{\circ} \mathrm{C}$ for protonation of IDA ligand. The yield of the conversion was evaluated in terms of the molar conversion, which is calculated by 


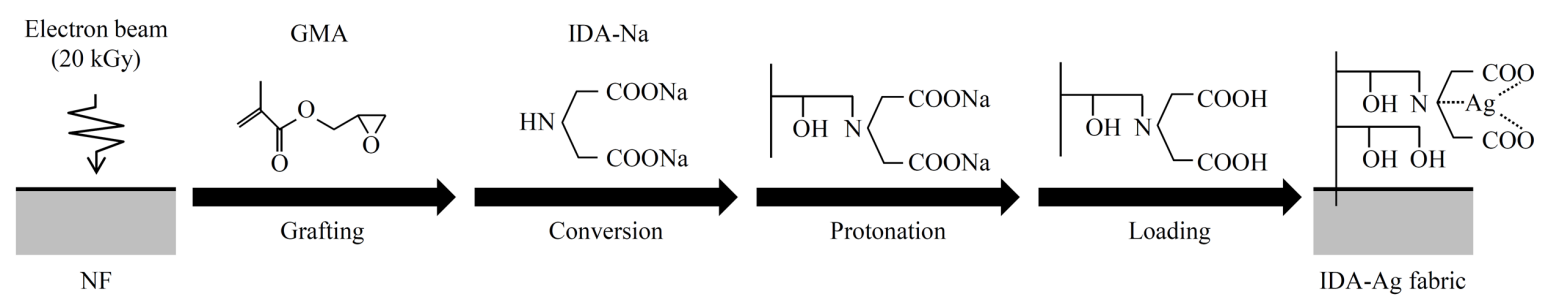

Figure 1. Schematic procedure of the IDA-Ag fabric.

$$
W_{2}=W_{0}+\left(W_{1}-W_{0}\right)\left[M_{c}(142-133)+\left(1-M_{c}\right)(142+18) / 142\right],
$$

The above equation converts to

$$
M_{c}=\left[142\left(W_{2}-W_{0}\right) /\left(W_{1}-W_{0}\right)-160\right] / 115,
$$

where $W_{2}$ is the weight of the IDA-ad, $M_{c}$ is the molar conversion, the numbers 142 , 18, and 133 were the molecular weights of GMA, water, and IDA-H, respectively.

The IDA-ad immersed into Ag solution with various concentrations at a certain pH to load Ag for obtaining the IDA-Ag fabric as the antibacterial material. The loading Ag was carried out by a dipping method. The IDA-ad was cut into $1 \mathrm{~cm}^{2}$ and was immersed in $50 \mathrm{~mL}$ of Ag solutions, and stirred for $24 \mathrm{~h}$. The loaded Ag amounts on the IDA-Ag fabric was calculated by analyzed Ag solutions before and after loading with inductively coupled plasma optical emission spectrometry (ICP-OES, SPECTRO Analytical Instruments GmbH, Spectro Arcos).

\subsection{Distribution of Ag on the IDA-Ag Fabric}

To evaluate a distribution of loaded Ag on the IDA-Ag fabric, a cross section was observed with a scanning electron microscope (SEM, Hitachi High-Technologies Co., Type N and SU3500), and an elemental mapping and line analysis of Na on the IDA-ad and Ag on the IDA-Ag fabric were evaluated with SEM-energy dispersive X-ray spectrometer (EDX, Hitachi High-Technologies Co, Type N).

\subsection{Evaluation of Antibacterial Effects for General Bacteria and Colitis Germ Legions}

To evaluate antibacterial effects and the release of Ag from the IDA-Ag fabric, the column mode water flow test was carried out by using the stream water with original pH 7. The IDA-Ag fabric was packed into the column (7 mm diameter, $5 \mathrm{~mm}$ height), and the stream water supplied continuously into the column at a flow rate of space velocity (SV) 50 and $500 \mathrm{~h}^{-1}$. Concentrations of released Ag were analyzed with ICP-OES.

Antibacterial test of the IDA-Ag fabric was evaluated by the column mode water flow test. The IDA-Ag fabric was packed into the column (40 mm diameter, 19 and $10 \mathrm{~mm}$ height for SV 50 and $500 \mathrm{~h}^{-1}$, respectively). The stream water was continuously supplied into the column at flow rates of SV 50 and $500 \mathrm{~h}^{-1}$. Number of general bacteria and Escherichia coli in influent and effluent of the column storage under $4^{\circ} \mathrm{C}$ were measured by Standard Agar Medium Method (SAMM) and the Defined Substrate Method, respectively, which are corresponding to the inspection method defined by Ministry of Health, Labour, and Welfare in Japan [25]. Furthermore, the sampling water detected Escherichia coli was measured number of general bacteria and colitis germ legions by SAMM- Hydrophobic Grid with Membrane Filter Method.

\section{Results and Discussions}

\subsection{Synthesis of the IDA-Ag Fabric}

The resulting synthesized GMA-g was DG 190\%. After that, the converting of the epoxy group to the IDA group, the molar conversion was $70 \%$ and the density of the IDA group was $1.7 \mathrm{mmol}-\mathrm{IDA} / \mathrm{g}$-ad.

A suitable condition for loading Ag on to the IDA-ad was investigated at various concentrations range from 0.05 to $3.00 \mathrm{mmol} / \mathrm{L}$ and $\mathrm{pH}$ range from 5 to 9 by batch mode. Figure 2 shows the amounts of loaded Ag on the IDA-Ag fabric with various Ag concentrations at $\mathrm{pH}$ 7. Ag amounts increased with Ag concentrations, and saturated $0.5 \mathrm{mmol}-\mathrm{Ag} / \mathrm{g}$-fabric with $3 \mathrm{mmol} / \mathrm{L}$ of Ag solution. However, $0.4 \mathrm{mmol}-\mathrm{Ag} / \mathrm{g}$-fabric loaded with 1 


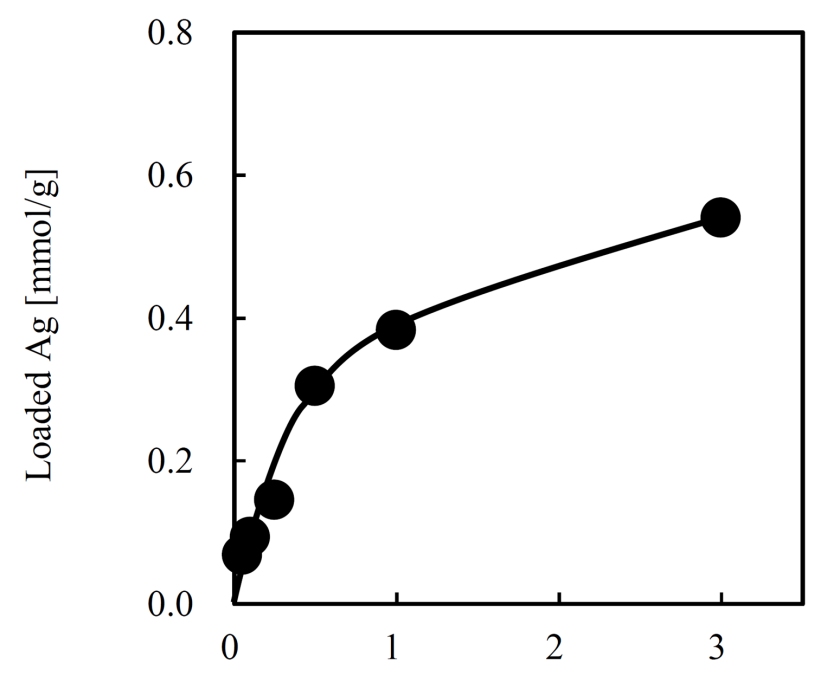

Ag concentration $[\mathrm{mmol} / \mathrm{L}]$

Figure 2. The amounts of loaded Ag on IDA-Ag fabric with various Ag concentrations.

$\mathrm{mmol} / \mathrm{L}$ which was one third of the saturation concentration was more effective condition. Therefore, the evaluation was advanced by the IDA-Ag fabric loaded with $1 \mathrm{mmol} / \mathrm{L}$ of Ag solutions. Figure 3 shows the amounts of loaded Ag on the IDA-Ag fabric at $\mathrm{pH}$ range from 5 to 9 adjusted the drinking water standard. Maximum and minimum Ag amounts of loaded were 0.35 and 0.46 mmol-Ag/g-fabric, respectively. Therefore, $\mathrm{pH}$ condition in the drinking water standard was not influenced to load Ag on to the IDA-ad, and the average of Ag amounts was $0.4 \mathrm{mmol}-\mathrm{Ag} / \mathrm{g}$-fabric.

The distribution of loaded Ag on the IDA-Ag fabric was evaluated by SEM and SEM-EDX. Figure 4(a) shows the SEM images of a cross section of the IDA-Ag fabric. Figure 4(b) shows elemental mapping of Naand the intensity of Na on IDA-ad before protonation by the line analysis, IDA functional groups was confirmed to load on the surface of fiber uniformly. Also, GMA was successfully grafted uniformly. Furthermore, Ag was confirmed to load on IDA layer uniformly (Figure 4(c)).

\subsection{Antibacterial Test}

First, the release of Ag from the IDA-Ag fabric to water was evaluated by the column mode water flow test. Figure 5 shows the release of Ag with the stream water at flow rate of SV 50 and $500 \mathrm{~h}^{-1}$. Especially, Figure 5(b) shows BV range focused from 0 to 350 in Figure 5(a). Maximum Ag concentration was 3 ppm just after starting the test. Ag amounts decrease with increased bed volume (BV: stream water volume/IDA-Ag fabric volume), and a concentration was $0.05 \mathrm{ppm}$ from BV 200 to 70000 at irrespective of flow rate. Therefore, the IDA-Ag fabric needs washing until BV 200 which Ag concentration stayed constant. Total release amounts at BV 70000 was no more than 30\%, the ion exchange capacities of loaded Ag was enough to apply for ions in stream water. This Ag release is also useful for antibacterial effects because concentrations corresponded to ranging from 0.025 to $0.1 \mathrm{ppm}$ which has antibacterial effects mentioned above [17].

Second, antibacterial effects of the IDA-Ag fabric was evaluated by the column mode water flow test with stream water at flow rate of SV $500 \mathrm{~h}^{-1}$ for three days on the site of Fukushima. Figure 6 and Figure 7 show an effect of the IDA-Ag fabric for general bacteria and colitis germ legions, respectively. Number of general bacteria and colitis germ legions in effluent was decreased with influent volume, although number of bacteria in influent varied widely. Especially, the high antibacterial effects for colitis germ legions were confirmed, which was completely disinfected until BV 6000 released 0.05 ppm of Ag shown in Figure 5. Therefore, the developed IDA-Ag fabric can be used at the least BV 70000, because 0.05 ppm of Ag release was confirmed until BV 70000 . 


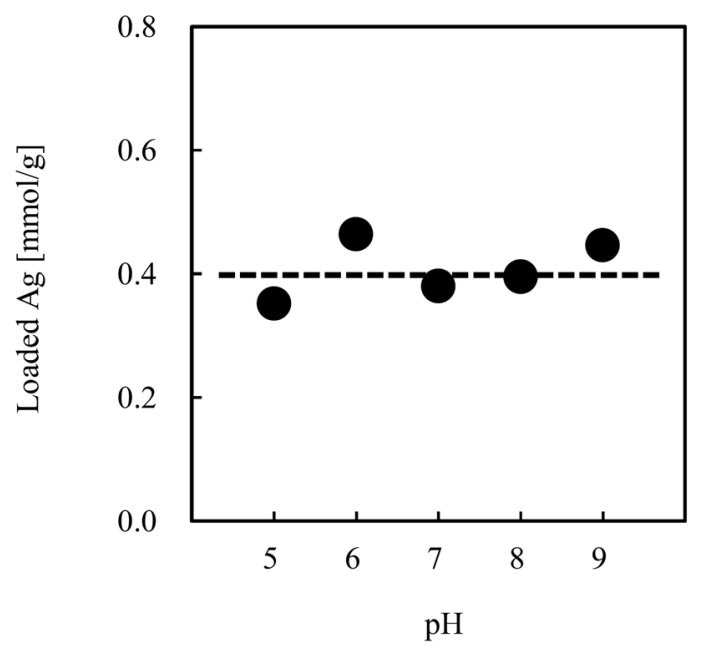

Figure 3. The amounts of loaded Ag on IDA-Ag fabric at various $\mathrm{pH}$.
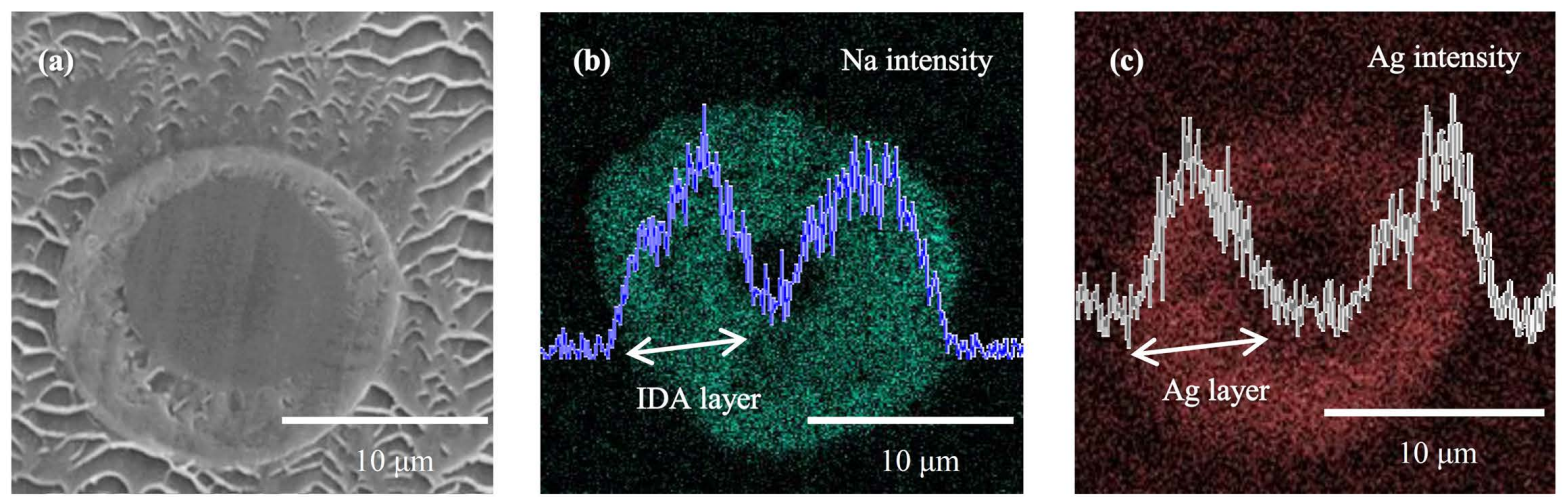

Figure 4. SEM images of a cross section; (a) IDA-Ag fabric, and SEM-EDX images and elemental intensity by the line analysis; (b) Na on the IDA-ad before protonation and (c) Ag on the IDA-Ag fabric.

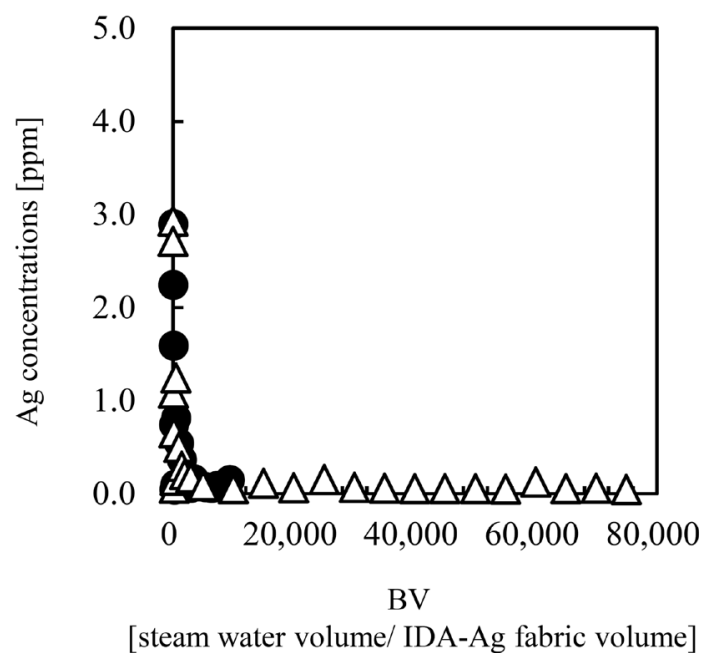

(a)

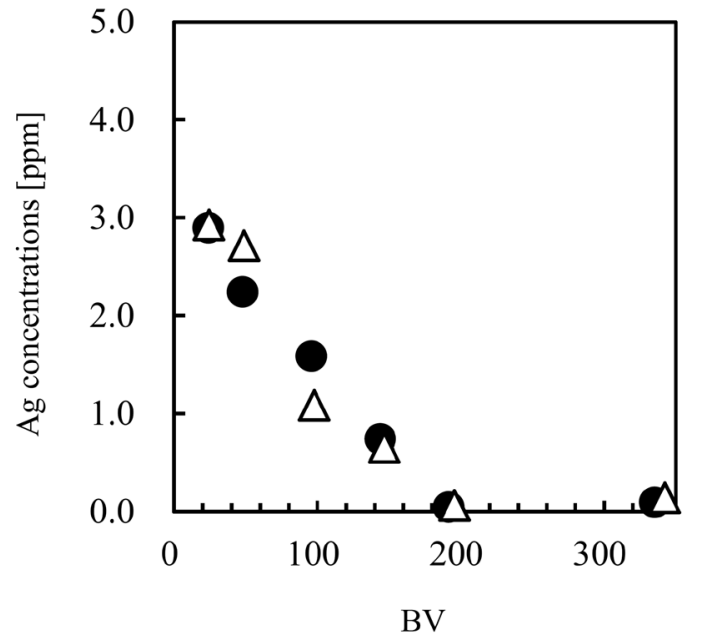

[steam water volume/ IDA-Ag fabric volume]

(b)

Figure 5. The release of Ag from the IDA-Ag fabric in column mode water flow test. (a) BV 0 - 80,000; (b) BV 0 - 350; (O) SV $50 \mathrm{~h}^{-1},(\Delta) \mathrm{SV} 500 \mathrm{~h}^{-1}$. 


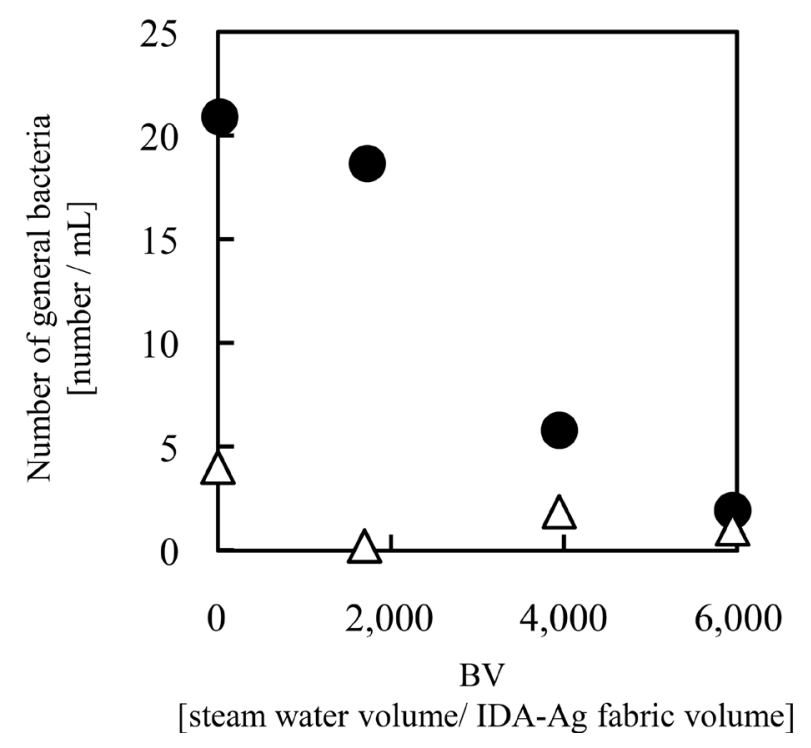

Figure 6. Antibacterial effects of the IDA-Ag fabric for general bacteria in column mode; $(\mathbf{)}$ influent (before IDA-Ag fabric), $(\Delta)$ effluent (after IDA-Ag fabric).

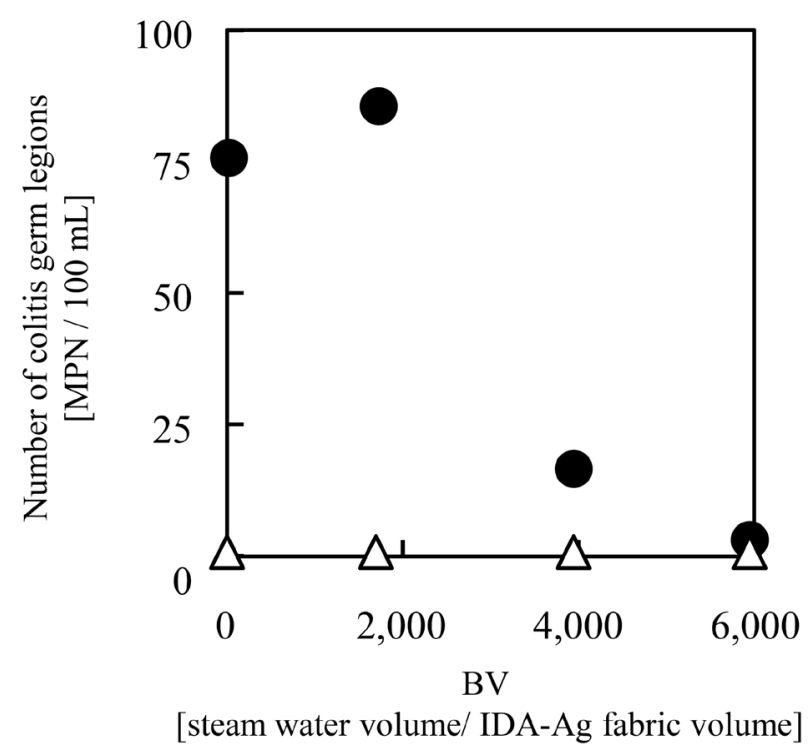

Figure 7. Antibacterial effects of the IDA-Ag fabric for colitis germ legions in column mode; $(\mathbf{O})$ influent (before IDA-Ag fabric), $(\Delta)$ effluent (after IDA-Ag fabric).

\section{Conclusions}

In this study, the antibacterial material was developed by RIGP to prevent the proliferation of bacteria on Cs adsorbent which has been developed to decontaminate disaster regions. The IDA-Ag fabric loaded Ag on the grafted trunk NF was successfully synthesized. In the process of loading Ag on IDA-ad, $0.4 \mathrm{mmol}-\mathrm{Ag} / \mathrm{g}$-fabric could be loaded in $1 \mathrm{mmol} / \mathrm{L}$ of Ag solutions, and $\mathrm{Ag}$ amount was stable at $\mathrm{pH}$ ranging from 5 to 9 including the drinking water standard (pH 5.8 to 8.6). To evaluate the distribution of loaded Ag on the IDA-Ag fabric, Ag was confirmed to load on IDA layer uniformly by SEM-EDX.

Antibacterial effects of the IDA-Ag fabric were evaluated by the column mode water flow test with the stream water at the flow rate of SV 50 and $500 \mathrm{~h}^{-1}$. The high antibacterial effects for general bacteria and colitis germ 
legions were confirmed until BV 6000. Especially, colitis germ legions could be completely disinfected. The release of Ag from the IDA-Ag fabric stayed constant at $0.05 \mathrm{ppm}$ which has antibacterial effects from BV 200 to 70000 at irrespective flow rate. Therefore, this IDA-Ag fabric can be used at the least BV 70000 .

\section{References}

[1] Shibata, T., Seko, N., Amada, H., Kasai, N., Saiki, S., Hoshina, H. and Ueki, Y. (2015) Development of an Adsorbent for Cs Removal Synthesized by Radiation-Induced Graft Polymerization. Journal of Ion Exchange, 26, 9-14. http://dx.doi.org/10.5182/jaie.26.9

[2] Yazgan, I., Du, N., Congdon, R., Okello, V. and Sadik, O.A. (2014) Biofunctionalized Poly(amic) Acid Membranes for Absolute Disinfection of Drinking Water. Journal of Membrane Science, 472, 261-271. http://dx.doi.org/10.1016/j.memsci.2014.07.048

[3] Lim, H.N., Huang, N.M. and Loo, C.H. (2012) Facile Preparation of Graphene-Based Chitosan Films: Enhanced Thermal, Mechanical and Antibacterial Properties. Journal of Non-Crystalline Solids, 358, 525-530. http://dx.doi.org/10.1016/j.jnoncrysol.2011.11.007

[4] Liu, C.X., Zhang, D.R., He, Y., Zhao, X.S. and Bai, R. (2010) Modification of Membrane Surface for Anti-Biofouling Performance: Effect of Anti-Adhesion and Anti-Bacteria Approaches. Journal of Membrane Science, 346, 121-130. http://dx.doi.org/10.1016/j.memsci.2009.09.028

[5] Qiu, S. and Lai, L. (2013) Antibacterial Properties of Recombinant Human Non-Pancreatic Secretory Phospholipase A $_{2}$. Biochemical and Biophysical Research Communications, 441, 453-456. http://dx.doi.org/10.1016/j.bbrc.2013.10.092

[6] Top, A. and Ülkü, S. (2004) Silver, Zinc, and Copper Exchange in a Na-Clinoptilolite and Resulting Effect on Antibacterial Activity. Applied Clay Science, 27, 13-19. http://dx.doi.org/10.1016/j.clay.2003.12.002

[7] Hsieh, J.H., Chang, C.C., Li, C., Liu, S.J. and Chang, Y.K. (2010) Effects of Ag Contents on Antibacterial Behaviors of TaON-Ag Nanocomposite Thin Films. Surface \& Coatings Technology, 205, 337-340. http://dx.doi.org/10.1016/j.surfcoat.2010.08.010

[8] Xi, B., Chu, X., Hu, J., Bhatia, C.S., Danner, A.J. and Yang, H. (2014) Preparation of Ag/TiO ${ }_{2} / \mathrm{SiO}_{2}$ Films via Photo-Assisted Deposition and Adsorptive Self-Assembly for Catalytic Bactericidal Application. Applied Surface Science, 311, 582-592. http://dx.doi.org/10.1016/j.apsusc.2014.05.112

[9] Hsieh, J.H., Yeh, T.H., Hung, S.Y., Chang, S.Y., Wu, W. and Li, C. (2012) Antibacterial and Tribological Properties of TaN-Cu, TaN-Ag, and TaN-(Ag, Cu) Nanocomposite Thin Films. Materials Research Bulletin, 47, 2999-3003. http://dx.doi.org/10.1016/j.materresbull.2012.04.101

[10] Xia, J.H., Hsu, C.T. and Qin, D.D. (2012) Cotton Fibers Nano-TiO $\mathrm{T}_{2}$ Composites Prepared by As-Assembly Process and the Photocatalytic Activities. Materials Research Bulletin, 47, 3943-3946. http://dx.doi.org/10.1016/j.materresbull.2012.07.022

[11] Zhao, X.J., Zhao, Q.N., Yu, J.G. and Liu, B.S. (2008) Development of Multifunctional Photoactive Self-Cleaning Glasses. Journal of Non-Crystalline Solids, 354, 1424-1430. http://dx.doi.org/10.1016/j.jnoncrysol.2006.10.093

[12] Chi, G.J., Yao, S.W., Fan, J., Zhang, W.G. and Wang, H.Z. (2002) Antibacterial Activity of Anodized Aluminum with Deposited Silver. Surface and Coatings Technology, 157, 162-165. http://dx.doi.org/10.1016/S0257-8972(02)00150-0

[13] Lu, Z.S., Xiao, J., Wang, Y. and Meng, M. (2015) In Situ Synthesis of Silver Nanoparticles Uniformly Distributedon Polydopamine-Coated Silk Fibers for Antibacterial Application. Journal of Colloid and Interface Science, 452, 8-14. http://dx.doi.org/10.1016/j.jcis.2015.04.015

[14] Zhao, Y., Wang, Z.-Q., Zhao, X., Li, W. and Liu, S.-X. (2013) Antibacterial Action of Silver-Doped Activated Carbon Prepared by Vacuum Impregnation. Applied Surface Science, 266, 67-72. http://dx.doi.org/10.1016/j.apsusc.2012.11.084

[15] Chen, C.-Y. and Chen, C.-Y. (2005) Formation of Silver Nanoparticles on a Chelating Copolymer Film Containingiminodiacetic Acid. Thin Solid Films, 484, 68-72. http://dx.doi.org/10.1016/j.tsf.2005.02.027

[16] Amato, E., Diaz-Fernandez, Y.A., Taglietti, A., Pallavicini, P., Pasotti, L., Cucca, L., Milanese, C., Grisoli, P., Dacarro, C., Fernandez-Hechavarria, J.M. and Necchi, V. (2011) Synthesis, Characterization and Antibacterial Activity against Gram Positive and Gram Negative Bacteria of Biomimetically Coated Silver Nanoparticles. Langmuir, 27, 9165-9173. http://dx.doi.org/10.1021/la201200r

[17] Martinez, S.S., Gallegos, A.A. and Martinez, E. (2004) Electrolytically Generated Silver and Copper Ions to Treat Cooling Water: An Environmentally Friendly Novel Alternative. International Journal of Hydrogen Energy, 29, 921932. http://dx.doi.org/10.1016/j.ijhydene.2003.06.002

[18] Seko, N., Basuki, F., Tamada, M. and Yoshii, F. (2004) Rapid Removal of Arsenic(V) by Zirconium(IV) Loaded Phosphoric Chelate Adsorbent Synthesized by Radiation Induced Graft Polymerization. Reactive \& Functional Poly- 
mers, 59, 235-241.

[19] Tamada, M., Seko, N. and Yoshii, F. (2004) Application of Radiation-Graft Material for Metal Adsorbent and Crosslinked Natural Polymer for Healthcare Product. Radiation Physics and Chemistry, 71, 221-225. http://dx.doi.org/10.1016/j.radphyschem.2004.03.044

[20] Seko, N., Tamada, M. and Yoshii, F. (2005) Current Status of Adsorbent for Metal Ions with Radiation Grafting and Crosslinking Techniques. Nuclear Instruments and Methods in Physics Research B, 236, 21-29. http://dx.doi.org/10.1016/j.nimb.2005.03.244

[21] Ueki, Y., Seko, N., Hoshina, H. and Tamada, M. (2007) Preparation of Polylactic Acid Nonwoven Fabric-Based Metal Adsorbent by Radiation-Induced Graft Polymerization. Journal of Ion Exchange, 18, 214-219. http://dx.doi.org/10.5182/jaie.18.214

[22] Kuraga, J., Trobradovic, H., Jyo, A., Sugo, T., Tamada, M. and Katakai, A. (2003) Behavior of Iminodiacetate Fiber in Column-Mode Adsorption of Lead (II). Journal of Ion Exchange, 14, 77-80. http://dx.doi.org/10.5182/jaie.14.Supplement_77

[23] Yamashiro, K., Miyoshi, K., Ishihara, R., Umeno, D., Saito, K., Sugo, T., Yamada, S., Fukunaga, H. and Nagai, M. (2007) High-Throughput Solid-Phase Extraction of Metal Ions Using an Iminodiacetate Chelating Porous Diskprepared by Graft Polymerization. Journal of Chromatography A, 1176, 37-42. http://dx.doi.org/10.1016/j.chroma.2007.10.107

[24] Konishi, S., Saito, K., Furusaki, S. and Sugo, T. (1992) Sorption Kinetics of Cobalt in Chelating Porous Membrane. Industrial and Engineering Chemistry Research, 31, 2722-2727. http://dx.doi.org/10.1021/ie00012a014

[25] Ministry of Health, Labour and Welfare in Japan (2003) The Method Established by the Minister of Health, Labour and Welfare Based on the Drinking Water Quality Standard. (In Japanese) http://www.mhlw.go.jp/file/06-Seisakujouhou-10900000-Kenkoukyoku/0000045850.pdf 